\title{
The role of bacteria in the treatment of cancer: A comprehensive review
}

\author{
Erfan Khadem ${ }^{1}$, Amir Hossein Nafari ${ }^{1}$, Ali Safarzadeh${ }^{1}$, Reza Falavand Jozaei ${ }^{1}$, Mohammad Almasian², Hossein Elyasi ${ }^{1 *}$
}

${ }^{1}$ Student Research Committee, Faculty of Medicine, Lorestan University of Medical Sciences, Khorramabad, Iran

${ }^{2}$ School of Medicine, Lorestan University of Medical Sciences, Khorramabad, Iran

\section{*Correspondence to: \\ Hossein Elyasi \\ hosseineliasy8373@gmail.com}

Received: 02 November 2019

Accepted: 30 January 2020

ePublished: 16 June 2020

Keywords:Cancer, Bacterial therapy, Toxin, Gene vector, Hypoxia

\section{Abstract}

Cancer is an important public health issue worldwide and is the main cause of death in the developed countries and the second cause of death in the developing countries. There are several treatments for cancer such as photodynamic therapy, surgery, chemotherapy, hormonal therapy, radiotherapy and immunotherapy. Current cancer treatments have various side effects, including the gradual resistance of cancer cells to treatment. The era of targeted cancer therapy has brought about new clinical approaches such as antibodies, small molecules, antiangiogenics, and antivirals. Yet even these strategies remain limited in their ability to accumulate in tumors and tumor penetration, which are the main obstacles in the treatment of cancer. Historic efforts to harness living organisms to fight cancer have recently been revived in the field of synthetic biology. Certain circulating bacteria can intrinsically home in on tumors, and can be engineered to controllably induce local cytotoxicity while remaining unobtrusive to the host system. Due to the ineffectiveness of conventional treatments such as chemotherapy and radiation therapy in advanced tumor stages, resistance to treatment and non-specificity of these treatments, with the advancement of studies in this field, it is hoped that bacterial therapy will add a new dimension to cancer treatment.

\section{Introduction}

Cancer can affect everyone, but the prevalence of this disease is different across local, national, and regional boundaries. Cancer is an important public health issue worldwide and is the main cause of death in the developed countries and the second cause of death in the developing countries. Cancer is a genetic and epigenetic disease, resulting from mutations in cells. Some mutations cause inactivation of genes which usually prevent abnormal cell proliferation. These genes are classically called tumor suppressor genes. Some mutations lead to the production of proteins which have oncogenic functions and play important roles in cell growth stimulation, and finally result in the transformation of normal cells into cancer cells and, as a result, uncontrolled cell proliferation occurs, because of some changes in biological pathways [1-6]. Cancer occurs in different organs such as lung, breast, colon and prostate [7]. Many studies have shown that the immune system reacts to tumors and tries to eliminate them [8]. Some cancer-related factors that influence survival include stage, tumor grade and histology, hormone receptor status, and human epidermal growth factor receptor 2 (HER2) status. Cancer survivorship depends on hormone receptor status, tumor grade and histology and human epidermal growth factor receptor 2 (HER2) status [9]. According to world health organization, smoking, being overweight or obese, eating an unhealthy diet, and being infected with the sexually transmitted HPV are the main factors that increase the chances of developing cancer [10]. Smoking is responsible for $80 \%$ of the worldwide lung cancer burden in males and at least $50 \%$ of the burden in females $[11,12]$ and some infections such as the human papilloma virus (HPV) and hepatitis are the causes of up to $25 \%$ of cancer cases in low- and middle-income countries [13]. In Korea as a developed country, the survival rate of cancer patients between 2009 and 2013 was 69.4\% [14]. It is estimated that the incidence of cancer will rise in 2030 and the number of patients suffering from cancer will be 2,135,000 in the United States [15]. Costs of treating cancer are rising and significant. The total annual economic cost of cancer in 2010 was estimated at almost US\$ 1.16 trillion [7].

Copyright (C) 2020 The Author(s). This is an open-access article distributed under the terms of the Creative Commons Attribution License (http://creativecommons.org/licenses/by/4.0), which permits unrestricted use, distribution, and reproduction in any medium, provided the original work is properly cited. 
It was estimated that there were 14.1 million new cases in the world in 2012 and cancer caused 8.2 million deaths, approximately $70 \%$ of deaths from cancer occurring in low- and middle-income countries $[10,16]$. Most cancers happen in the less developed countries in the world, with $60 \%$ of cancers and $70 \%$ of deaths from cancer occurring in Africa, Asia, and Central and South America [17]. The most commonly affected body systems and organs include the respiratory system, breast, and the genitourinary system. In 2016, 1,685,210 new cancer diagnoses and 595,690 cancer deaths occurred in the United States. Both the number of estimated new cases and estimated deaths from cancer are higher among men than among women in the US. The most common cancers in men are prostate $(21 \%)$, lung and bronchus (14\%), colon and rectum (8\%) and urinary bladder (7\%), but the highest number of deaths are from the cancers of lung and bronchus (27\%), prostate (8\%), colon and rectum (8\%), pancreas (7\%). In women, the most common estimated new cases are the cancers of breast (29\%), lung and bronchus (13\%), colon and rectum (8\%), and uterine corpus (7\%), but most deaths are due to the cancers of lung and bronchus (26\%), breast (14\%), colon and rectum (8\%) and pancreas (7\%) [18]. There is a strong relationship between cancer and age, prevalence in the youngest age group (0-14 years) are about 10 per 100000 , increasing to 150 per 100000 by $40-44$ years and to more than 500 per 100 000 by $60-64$ years (7). Liver cancer has the fastest growing rate among all cancer sites among both men and women [19].

There are several treatment methods for cancer based on the type, location and stage of the cancer $[20,21]$ such as photodynamic therapy [22], surgery [23], chemotherapy [24], hormonal therapy [25], and immunotherapy [26]. Current cancer treatments have various side effects such as the gradual resistance of cancer cells against treatment [27], skin and hypersensitivity reactions [28], diarrhea, dyspnea, dysuria, fatigue, hot flashes [29], nausea, and neutropenia [30]. Sexual dysfunction and infertility are some of the late effects of cancer treatment [31] and they can also happen in both males and females who had been treated for cancer in their childhood $[32,33]$. Many of the treatments we use for cancer can influence the reproductive hormones, which are important for the maintenance of normal bone remodeling, leading to bone loss [34]. For example, chemotherapy for breast cancer with taxanes, anthracyclines and HER-2-targeted aromatase inhibitors often result in neuropathy [35], cardiomyopathy, congestive heart failure [36], and osteoporosis, respectively [37] and lung cancer treatment with EGFR inhibitors can cause severe acneiform rash and immunotherapy drugs lead to immune mediated toxicities, including pneumonitis, colitis and nephritis [38]. It has been shown that liposomal doxorubicin which is used for ovarian cancer treatment has various side effects such as stomatitis, rash, mucositis and vomiting [39].

Chemotherapy can induce drug tolerance, nausea, fatigue, loss of appetite, uterine bleeding, dyspareunia, vaginal dryness or discharge, hot flushes, loss of libido, optical difficulties (cataract), deep venous thrombosis, venous thromboembolism, embolism, and pulmonary, cardiovascular, ischemic, cerebrovascular and sexual problems. Medications used in chemotherapy can also act as carcinogens [49-53]. Psychological issues consist of depression, anxiety, guilt, fear of recurrence, body image difficulties, loneliness and anger [54]. Chemotherapy is responsible for insomnia in cancer patients because of its role in the occurrence of headaches, digestive symptoms, and nausea [55]. Chemother- apy appears to be most harmful for patients who have a good performance condition [60]. Early effects of radiotherapy can be nausea, skin erythema, diarrhea, and dry or moist desquamation of the skin, while the late effects are vascular damage, neural damage, radiation-induced fibrosis and a range of endocrine and growth-related effects and atrophy [56]. It has been shown that radiotherapy can be a cause of secondary malignancies [57]. Immunotherapy induces inflammation of the colon and the pituitary gland [58]. Hormonal therapy may result in thromboembolic events, peripheral edema, and increased appetite [59].

Bacterial therapy can be used for some diseases. Wild type or recombinant lactic acid bacteria (LAB) can be used as an alternative treatment for inflammatory bowel disease (IBD) and mucositis. It has been shown that probiotic LAB especially recombinant L. lactis could be a sufficient treatment agent for irritable bowel syndrome (IBS), because of their ability to produce anti-inflammatory peptides such as defensins, cathelicidins and histatins [40]. Furthermore, LAB can produce anti-inflammatory vitamins and can be used for IBD treatment and as a source of essential nutrients of which IBD patients often do not get enough [43]. In another study engineered lactic acid bacterium NCDO 2118 was used to produce oxidative enzyme, 15-lipoxygenase-1 (15-LOX-1) which acts as a catalyst in the production of several anti-inflammatory agents, such as protectins and lipoxins [41]. Bifidobacteria can play a role in the improvement of the clinical symptoms of IBD [32]. Various bacteria such as Escherichia coli, Bifidobacterium bifidum, Bifidobacterium lactis and Lactococcus lactis have been used to cure eczema patients because of their ability to produce Th2 cytokines and to stimulate IL-10 [42-46]. Lactobacillus plantarum, Propionibacterium freudenreichii and Enterococcus faecium M-74 are used for the treatment of hypercholesterolemia and cardiovascular diseases due to their ability to reduce serum cholesterol levels by affecting the expression of a gene encoding cholesterol oxidase $[47,48]$.

The era of targeted cancer therapy has brought new clinical approaches such as the use of antibodies, small molecules, antiangiogenics, and antivirals. Yet even these strategies remain limited in their tumor penetration and their abilities to accumulate in tumors, which are prevailing obstacles in the treatment of cancer. Historic efforts to harness living organisms to fight cancer have recently been revived by synthetic biology [61, 62]. Certain circulating bacteria can intrinsically home in on tumors, and can be engineered to controllably induce local cytotoxicity while remaining unobtrusive to the host system. The observation that bacteria accumulate preferentially in tumors has prompted the investigation of the use of a number of strains for cancer therapy, including E. coli, and S. typhimurium, both of which have exhibited safety and tolerance in human clinical trials. S. typhimurium was initially shown to mediate anti-tumor effects through recruitment of the host immune system and by competing with cancer cells for nutrients [63-65]. Subsequently, the engineered production of therapeutic cargo was achieved through simple genetic modifications. As a next step, synthetic biology seeks to add controlled and dynamic production of cargo by utilizing genetic circuits that have sophisticated sensing and delivery capabilities, such that bacteria can sense tumor-specific stimuli and self-regulate cargo production as necessary $[66,67]$.

While these fast-paced advances have shown great potential, the main challenges in engineering bacteria for tumor therapy are the need for better control of inherent overgrowth and the 
limited ability of bacteria to penetrate tumor environments, despite their enhanced accumulat compared to passively circulating agents [68].

\section{Gene therapy vectors:}

Gene transfer systems can be divided into non-biological groups (such as chemicals and physical methods making plasmid DNA transfer to mammalian cells possible) and biological (viruses and bacteria). Like viruses, the inherent biological properties of bacteria allow the efficient delivery of DNA to cells or tissues, but in terms of safety, it is preferable to viral infections. Today, there are two broad methods for using bacteria as vectors [69-71].

\section{Bacterial replication}

Ideal antitumor treatment is selective tumor removal with minimal negative effect on normal cells. To reach this goal, features of cancerous cells that distinguish them from normal tissues should be well known. At first, the specificity of the tumor is specific to the nature of the hypoxia of solid tumors. Necrotic areas provide nutrients such as purines and suitable conditions for the growth of anaerobic bacteria. The chemotaxis of bacteria to materials in necrotic areas such as aspartate, serine, citrate, ribosomes and galactose produced by cancer cells has been observed $[72,73]$.

\section{Transfer of intracellular plasmid}

Transmission of plasmid DNA into mammalian cells by bacteria is a powerful tool for expressing heterologous proteins in different cells. Transmission of the genetic material is achieved through the complete penetration of the bacteria into target cells. Various bacteria including Salmonella, Listeria and Escherichia coli have been studied. The bacterial species used are classified according to their location in the host cell: a group in the cytoplasm (Listeria, Shigella), a group in the vacuole (Salmonella, Yersinia) and another group in the extracellular space (Agrobacterium). On the other hand, one of the traditional methods of using bacteria as vectors is targeted gene expression in cancer cells through the targeted setting of gene expression. Gene expression is regulated at different levels, but, typically, is more prevalent in the transcription level. SLPI is a serine protease inhibitor whose specific tissue expression is highly regulated at the transcriptional level. The promoter of this gene can be a good candidate for targeting gene expression in lung cancer through the use of bacterial plasmids [74-77].

\section{Bacterial toxins and cancer therapy}

The spectrum of toxins produced by bacteria is vast, among which the tetanus, botulinum and diphtheria toxins can be mentioned. In the treatment of cancer, toxins can interfere with proliferation and at reduced levels with the control of apoptosis, differentiation and duplication. Bacterial toxins that overturn the cell cycle are classified as cyclomodulins. Bacterial toxins act in two ways on cancer cells $[78,79]$.

\section{Bacterial toxins bind to tumor surface anti-}

\section{gens}

Diphtheria toxin (DT) is attached to the surface of the cells expressing the HB-EGF (Heparin-binding epidermal growth factor) precursor and through the endothelium mediated by clathrin and after several changes after translation; it catalytically activates and ultimately results in the inhibition of protein synthesis, the lyse of cells, and the induction of apoptosis. Another example is endotoxin CPE produced by strain A of Clostridium perfringens, the cause of diarrhea and vomiting, in which the end domain of $\mathrm{C}$ is responsible for its ability to bind to the receptor and the end domain of $\mathrm{N}$ has toxic effects. Studies have shown that, in pancreatic cells, pure CPE leads to tumor necrosis and inhibits tumor growth in the living creature. The effect of this toxin has been investigated on gastric, lung, and colon cancers, however, it is necessary to consider the long-term treatment effectiveness and lack of toxicity in living creatures [80-82].

\section{Bacterial toxins conjugate with ligands}

Protein toxins like pseudomonas exotoxin, diphtheria and ricin toxin can play a role in the treatment of very lethal cancers. However, these toxins require a special place on the surface of cancerous cells for effective treatment. This problem can be solved by removing the binding site to the toxin receptor and conjugating it with monoclonal antibodies and growth factors attached to cancer cells [83].

Cytolethal distending toxin is a bacterial toxin produced by gram-negative bacteria. Its mechanism of action is unique in that it enters the eukaryotic cell and breaks the double-stranded DNA; this causes the activation of DNA damage mechanisms and stops the cell at the G2/M stage. The affected cell enlarges and eventually apoptosis occurs. The enzyme component of this toxin can conjugate to the ligand and can be considered as an appropriate therapeutic target [84].

\section{Bacterial spores in the treatment of cancer}

Most anaerobic bacteria survive as spores in oxygen-rich conditions although they do not have the ability to grow and proliferate, however, when they are in suitable conditions, such as the dead areas of the tumor, spores sprout and bacteria grow. This feature allows for targeting cancer [85].

Spores of genetically modified strains of C. novyi NT lack deadly toxin and have targeted function on normal cells without side effects. A remarkable lysis of tumor tissue has been observed in mice receiving intra-tumor injection of Clostridium histolithium spores, and in intravenous injection of Clostridium perfringens spores. In addition, Clostridium was found only in the tumors of the mice receiving intravenous injections of the bacterium $[86,87]$.

\section{Bacteria as immune agents}

The use of the immune system in cancer treatment is a promising approach. In this therapeutic system, stimulation of the immune system is used to destroy cancer cells. The most important problem with this method is the ability of the tumor to escape the immune system and cause weak tolerance and immunogenicity. In some cases, the body considers a cancerous antigen to be a self-antigen; therefore, the bacteria are used to enhance the immunogenicity of the cancerous cells $[88,89]$.

\section{Recombinant anaerobic bacteria}

Brown et al. first showed that the necrotic areas in human solid tumors could be used to target cancer treatment to tumors 
by using a genetically engineered non-pathogenic strain of the bacterial genus Clostridium. This genus contains a great and heterogeneous group of spore-forming, gram-positive bacteria that become vegetative and grow only in the lack of (or at very low levels) of oxygen [90, 91]. Malmgren et al. were the first to reveal this phenomenon by detecting that tumor-bearing mice died of tetanus within 48 hours of the intravenous injection of Clostridium tetani spores, while non-tumor-bearing animals were unaffected. Möse et al. later reported that a nonpathogenic clostridial strain, (C. butyricum M-55), localized and developed in solid Ehrlich tumors in mice, causing broad lysis without any associated effect on usual tissues. Similar reports were soon presented and extended by several researchers by using tumors in mice, rats, hamsters and rabbits, and with clinical trial studies with patients having cancer $[92,93]$. While the anaerobic bacteria did not meaningfully alter tumor control or eradication, these important clinical reports confirmed that spores of nonpathogenic strains of clostridia could be administered without harm, that the spores sprout in the necrotic areas of the tumors, and that lysis in these tumor areas can occur. This is an important difference over a similar approach using genetically modified, live weakened Salmonella, which, even though producing outstanding colonization of transplanted tumors in mice, formed only marginal colonization of human tumors in a Phase I clinical trial $[94,95]$. The causes for the difference between the rodent and human tumors in colonization by Salmonella are unknown. But, colonization by clostridia is different from that of the Salmonella bacterium in being dependent on hypoxic necrotic areas, which are similarly common in human and rodent tumors. Furthermore, as noted above, brilliant colonization of human tumors has been observed subsequent to intravenous injection of clostridial spores. The Clostridium used in clinical trials was a strain of C. sporogenes that was renamed C. oncolyticum to reflect the lysis that occurs in human tumors. This strain has been genetically changed to express an enzyme of E. coli, cytosine deaminase, which can alter the non-toxic 5-fluorocytosine to the toxic anticancer drug 5-fluorouracil. Animal interventions have shown the effectiveness of this method and clinical trials are planned. Furthermore, other enzymatic prodrug systems for arming clostridia are in progress, including CB 1954 (BOX 2), which, once activated by E. coli nitroreductase, kills non-cycling cells efficiently and is therefore expected to have superior activity against cells in hypoxic areas [96-99].

\section{Genetically modified recombinant toxins}

The manufacture of immunotoxins by chemical systems is expensive since it needs huge amounts of toxins and antibodies. Also, the chemical conjugation methods used yield heterogeneous products, and chemical derivatization often affects antigen binding. It is possible to overcome these problems and to make cytotoxic factors by genetic modification. The PE and DT have been used to produce modified toxins in E. coli. Ricin-derived molecules have been hard to manufacture perhaps because the $\mathrm{A}$ chain of the plant toxin must be attached to the recognition domain of the cell via a disulfide bond, and subunits that are linked to disulfide are hard to create in bacteria [100,101]. Adding of a proteolytic cleavage arrangement might help to overcome this problem. PE x-ray crystallographic construction has been used for the synthesis of genetically modified recombinant toxins. The particular binding of PE to target cells happens through an interaction of cellular PE receptors with domain I. The connection of domain II with domain I happens between Gly253and Glu252. Therefore, in making recombinant toxins, domain I was deleted, and the $\mathrm{COOH}$-terminal-amino acid of different growth factors and other targeting molecules were bonded straight to Gly253 of PE (a few added amino acids have been added as a link between the COGH-terminus of the growth factor and Gly253 of $\mathrm{PE}$ occasionally, to make cloning more viable) [102-104]. One of the widely studied molecules is TGF-at-PE4O, which was built by replacing transforming growth factor alpha with domain I of PE (TGF-ot). In this chimeric toxin, the $23-\mathrm{kD}$ domain I is changed by the $6-\mathrm{kD}$ growth factor, to create a chimeric toxin that selectively attaches to and kills cells with receptors of epidermal growth factor (EGF). The expression vector used for the making of TGF-ot-PE40 and other PE-based chimeric toxins in E. coli encloses the promoter of bacteriophage T7, an effective ribosome binding site and an Nde I site (CATATG), which encrypts a methionine initiation codon where targeting ligands can be simply inserted. The gene encoding the phage T7 polymerase is inserted into the E. coli chromosome following a lac promoter so that it can be induced by the addition of isopropylthiogalactoside (IPTG). TGF-c-PE40, like other chimeric toxins made in E. coli, is stored in huge amounts within the cell in insoluble aggregates (inclusion bodies). Inclusion bodies are easily isolated and can contain up to $90 \%$ recombinant protein in an insoluble form after cell disruption. The protein is then dissolved in a strong denaturant such as $7 \mathrm{M}$ guanidine-HCI, renatured, and can be purified to near homogeneity in two or three steps by conventional column chromatographic ways. TGF-a-PE40 binds to EGF receptor-containing cells with about the same affinity as TGF-c, and its toxicity on these cells is directly related to the number of receptors present [105-108].

\section{Tumor-targeting bacteria}

One of the strong points of bacterial therapy is the ability to specifically target tumor sites. In 1964, a series of reports described the use of nonpathogenic Clostridia in experimental tumor models. The rationale for using Clostridium is that it is an obligate anaerobic bacterium. Therefore, when injected into a body, the spores replicate and develop only in hypoxic regions. In hosts with advanced cancer, these hypoxic regions can be found and Clostridium is presumed to develop and proliferate in these oxygen-poor areas while being absent from well-oxygenated healthy tissues [109, 110]. Moreover, this selective targeting is associated with the death of tumor cells. Not all spore-forming bacteria are effective, and the spore-forming microorganisms Bacillus mesentericus and Bacillus subtilis do not produce oncolysis. These results indicate that although the obligate anaerobic phenotype of Clostridium is probably the basis for their ability to specifically target necrotic areas of tumors, other factors may be involved. Although promising, the strategy shows major limitations. First, the oncolytic effect is restricted to large, well-established tumors but is undetectable in smaller metastatic nodules, probably because these lesions lack hypoxic regions $[111,112]$. Second, Clostridium-dependent lysis is found in the center of large tumors, leaving the liquid necrotic center surrounded by a better-oxygenated layer of malignant cells that constitute the seed for the re-growth of the tumor [113]. Finally, some toxicity is observed in preclinical mouse models. Fox et al. 
placed the Escherichia coli cytosine deaminase gene into Clostridium beijerinckii by using it as the Clostridium expression vector and produced an increased cytosine deaminase activity in the extracts of the transformed bacteria. Recent in vivo studies of the use of Clostridia as tumor vectors have focused on their potential in gene therapy and controlled gene expression by use of radio-inducible promoters. Another group investigating Clostridium in combination with chemotherapy has reported significant antitumor activity (Dang et al. 2001). Many years after the first injection of Clostridium spores into tumors, various advances have shown promise for Clostridium as a tumor-targeting therapeutic vector [114].

\section{Discussion and conclusion}

In 1868, German doctors W. Busch and F. Fehleisen separately observed that some hospitalized cancer patients have accidentally recovered after an infection with the Streptococcus pyogenes in the form of Erysipelas. In 1890, William B Colley, a physician at New York Memorial Hospital, for the first time, defined bacteria as an anticancer agent. He observed tumor regression several times after infection with a pathogenic bacterium. In 1976, Bruce, Morales et al. reported successful treatment of bladder cancer with Bacillus Calmette-Guérin (BCG). Numerous scientists from then on, and even today, selectively targeted cancer cells with weakened, engineered, and alive microorganisms, such as mycobacterium, bifidobacterium, bacillus, salmonella, and listeria $[115,116]$.

Cancer treatment encounters major challenges, including the specificity of treatment. Perfect therapy will be able to eliminate selected tumor cells with minimal side effects for normal body cells. Furthermore, chemotherapy and radiotherapy produce significant problems. Resistance to cancer treatment in patients with advanced tumors has led to the need for alternative cancer treatments $[117,118]$.

When bacteria are injected systemically, the bacteria accumulate in tumors and in the areas far from vessels which are hypoxic and necrotic areas. When bacteria begin to produce therapeutic molecules, they spread to living tissues. The concentration of bacterial molecules in the distal region of tumors is greatest and as long as the expression of proteins continues, it stays constant. Systemic injection of chemotherapy molecules is spread into the blood vessels of the tumor. The highest molecular concentration of chemotherapy is in the bloodstream [119, 120].

After the first general observations of Colly, scientists have made use of specific species of anaerobic bacteria that grow in the tumor's hypoxic and necrotic tissue and die when in contact with the oxygenated parts around the tumor and are not harmful for other parts of the body. These findings suggest that bacteria can be used as oncolytic agents. However, bacteria do not consume all of the malignant tissue, resulting in the need for a combination of chemotherapy treatment. Therefore, bacteria can be used as chemotherapeutic sensitive agents $[121,122]$.

Bacterial products, such as endotoxins, have been partially tested for cancer treatment. Bacterial toxins can be used to kill tumors and as cancer vaccines. Bacteria can be used as agents for the transfer of anticancer drugs and serve as vectors for delivering therapeutic genes. Spores of anaerobic bacteria are also used for the mentioned strategies because they sprout, activate and multiply in the hypoxic regions of tumors [123].

Compared with targeted cancer treatments, bacteria have a special place, which is associated with three unique bacterial properties. Almost all tumors have low oxygen or hypoxia and anaerobic bacteria prefer such environments. In addition, bacteria can be easily manipulated and can overcome the limitations of conventional cancer treatments. Also, unlike other therapies, such as radiation therapy, bacterial therapy has a good penetration into tumor tissues. However, the problems of bacterial treatment related to the toxic nature of bacteria and their genetic instability cannot be ignored. Significant efforts have been made to overcome these problems including the use of engineered and weakened bacteria, recombinant DNA technology, and also the simultaneous use of this treatment with other therapies, such as chemotherapy, heat shock proteins, heavy metals and radiation $[124,125]$.

Various applications of bacteria, including live and weakened bacteria as anticancer agents and vector carriers of genes, spores as factors compatible with the environment and tumor conditions, and bacterial toxins for destroying cancer cells, have been studied so far. These results indicate that the use of bacteria is a promising treatment for cancer. In addition, a variety of bacterial approaches to treating cancer especially in Phase 1 clinical trials of cancer patients based on basic knowledge of cancer have become possible. Due to the inability of conventional treatments such as chemotherapy and radiation therapy in advanced tumor stages, resistance to treatment and non-specificity of these treatments, with the advancement of studies in this field, it is hoped that bacterial therapy can add a new dimension to the treatment of cancer.

\section{Funding}

The authors received no funding

\section{Conflict of interest}

The authors declared that they have no conflicts of interest.

\section{Ethics approval}

Not required

\section{Funding/Support None.}

\section{References}

1. Souho T, Lamboni L, Xiao L, Yang G. Cancer hallmarks and malignancy features: Gateway for improved targeted drug delivery. Biotechnol Adv. 2018; (18): 30133-2.

2. Kranthi TKK, Baba AB, Kowshik J, Reddy GB, Nagini S. Gedunin, A Neem Limonoid in Combination With Epalrestat Inhibits Cancer Hallmarks By Attenuating Aldose Reductase-Driven Oncogenic Signaling In SCC131 Oral Cancer Cells. Anticancer Agents Med Chem. 2018 Jul 30.

3. Maley et al. "Classifying the evolutionary and ecological features of neoplasms." Nat Rev Cancer 2017; 17(10): 605619.

4. Calin, George A, Carlo M. Croce. "MicroRNA signatures in human cancers." Nat Rev Cancer 2006; 6(11): 857.

5. Ezzati, Majid, et al. Role of smoking in global and regional cancer epidemiology: current patterns and data needs. Int J Cancer 2005; 116(6): 963-971.

6. World Health Organization. The Global Burden of Disease: 2004 Update. Geneva: World Health Organization; 2008.

7. Wild Christopher P, Bernard W. Stewart, eds. World cancer 
report 2014. World Health Organization, 2014.

8. Pradeu T, Edwin L. Cooper. The danger theory: 20 years later." Front Immunol. 2012 Sep 17; 3: 287

9. Kodytkova D, Bajciova V, Krejci D, Zapletalova M, Dusek V, Jarkovsky J, Muzik J, D Klimes D. Trends in incidence of childhood cancers in the Czech Republic: populationbased analysis of national registries (1994-2014). Neoplasma. 2018; 65(4):620-629.

10. Cancer Fact sheet $\mathrm{N}^{\circ} 297$. World Health Organization. February 2018. Retrieved 21 March 2018.

11. Ezzati M , S Jane Henley S, D Lopez A, J Thun M . Role of smoking in global and regional cancer epidemiology: current patterns and data needs. Int J Cancer 2005; 116(6): $963-$ 971.

12. Ezzati M, D. Lopez A. Estimates of global mortality attributable to smoking in 2000." The Lancet 2003; 362(9387): 847-852.

13. Plummer M, de Martel C, Vignat J, Ferlay J, Bray F, Franceschi S. Global burden of cancers attributable to infections in 2012: a synthetic analysis. Lancet Glob Health. 2016 Sep; 4(9): e609-16.

14. Cancer Fact sheet $\mathrm{N}^{\circ} 297$. World Health Organization. February 2018. Retrieved 21 March 2018.

15. Rahib. "Projecting cancer incidence and deaths to 2030: the unexpected burden of thyroid, liver, and pancreas cancers in the United States." Cancer research 2014; 74(11): 2913-2921.

16. Richman DM et al. Beyond gastric adenocarcinoma: Multimodality assessment of common and uncommon gastric neoplasms. Abdom Radiol (NY). 2017 Jan; 42(1): 124-140.

17. Gulland, Anne. "Global cancer prevalence is growing at" alarming pace," says WHO.” BMJ 2014; 348.

18. Siegel, Rebecca L., Kimberly D. Miller, Ahmedin Jemal. "Cancer statistics, 2016." CA: a cancer journal for clinicians 2016; 66(1): 7-30.

19. Ryerson A. "Annual report to the nation on the status of cancer, 1975-2012, featuring the increasing incidence of liver cancer." Cancer. 2016 May 1; 122(9): 1312-37.

20. Hodi F. Stephen P. Improved survival with ipilimumab in patients with metastatic melanoma. N Engl J Med 32010; 63(8): 711-723.

21. Miller E. Cancer treatment and survivorship statistics, 2016. CA: a cancer journal for clinicians 2016; 66(4): 271-289.

22. Dolmans, Dennis EJGJ, Dai Fukumura, Rakesh K. Jain. Photodynamic therapy for cancer." Nat rev cancer 2003; 3(5): 380.

23. Hüseret al. "Systematic review and meta-analysis of the role of defunctioning stoma in low rectal cancer surgery. Ann Surg 2008; 248(1): 52-60.

24. Wagner R. Chemotherapy in advanced gastric cancer: a systematic review and meta-analysis based on aggregate data. J Clin Oncol 2006; 24(18): 2903-2909.

25. Ramirez L. Hormonal therapy for the management of grade 1 endometrial adenocarcinoma: a literature review. Gynecol Oncol 2004; 95(1): 133-138.

26. Yang Y. Cancer immunotherapy: harnessing the immune system to battle cancer. J Clin Invest. 2015 Sep; 125(9): 3335-7.

27. Safarzadeh E, Sandoghchian Shotorbani S, Baradaran B. Herbal medicine as inducers of apoptosis in cancer treatment. Adv Pharm Bull 2014; 4.Suppl 1: 421.

28. [28] Gordon T. Recurrent epithelial ovarian carcinoma: a randomized phase III study of pegylated liposomal doxorubicin versus topotecan. J Clin Oncol 2001; 19(14): 33123322.

29. Basch A. Symptom monitoring with patient-reported outcomes during routine cancer treatment: a randomized controlled trial: J Clin Oncol 2016 34(6): 557.

30. Iwamoto, Takuya. "Clinical application of drug delivery systems in cancer chemotherapy: review of the efficacy and side effects of approved drugs." Biol Pharm Bull 2013; 36(5): 715-718.

31. Schover et al. "Sexual dysfunction and infertility as late effects of cancer treatment." EJC Suppl 2014; 12(1): 41-53.

32. Barton L. Infertility, infertility treatment, and achievement of pregnancy in female survivors of childhood cancer: a report from the Childhood Cancer Survivor Study cohort. The lancet oncology 2013; 14(9): 873-881.

33. Wasilewski-Masker, K., et al. "Male infertility in long-term survivors of pediatric cancer: a report from the childhood cancer survivor study." J Cancer Surviv 2014; 8(3): 437-447.

34. Coleman R. Bone health in cancer patients: ESMO Clinical Practice Guidelines. Ann Oncol. 2014; 25: suppl 3: 124-137.

35. Edgardo R, Cianfrocca M. Overview of neuropathy associated with taxanes for the treatment of metastatic breast cancer. Cancer Chemother Pharmacol. 2015; 75(4): 659-670.

36. Curigliano D, Cardinale D, Suter T, Plataniotis G, de Azambuja E, et al. Cardiovascular toxicity induced by chemotherapy, targeted agents and radiotherapy: ESMO Clinical Practice Guidelines. Ann Oncol. 2012; 23(suppl 7): 155- 166.

37. Conte, PierFranco, and Antonio Frassoldati. "Aromatase inhibitors in the adjuvant treatment of postmenopausal women with early breast cancer: putting safety issues into perspective." Breast J. 2017; 13(1): 28-35.

38. Chambers, Suzanne K. A systematic review of the impact of stigma and nihilism on lung cancer outcomes. BMC cancer 2012; 12(1): 184.

39. Gordon R, Fleagle JT, Guthrie D, Parkin DE, Gore ME, Lacave AJ. Recurrent epithelial ovarian carcinoma: a randomized phase III study of pegylated liposomal doxorubicin versus topotecan. J clin oncol 2001; 19(14): 3312-3322.

40. Carvalho RD, do Carmo F, de Oliveira Junior A, Langella $\mathrm{PH}$,. Use of wild type or recombinant lactic acid bacteria as an alternative treatment for gastrointestinal inflammatory diseases: a focus on inflammatory bowel diseases and mucositis. Front Microbiol. 8 (2017): 800.

41. Carvalho DO. Oral administration of Lactococcus lactis expressing recombinant 15-lipoxygenase-1 (15 LOX-1) modulates chemically induced colitis in mice." Medical Research Archives 2016; 4(7): 1.

42. Saez-Lara $\mathrm{f}$. The role of probiotic lactic acid bacteria and bifidobacteria in the prevention and treatment of inflammatory bowel disease and other related diseases: a systematic review of randomized human clinical trials. BioMed Res Intern. 2015; 6: 3-7.

43. Levit R, de Giori G, Savoy JG. LeBlanc. Vitamin Producing Lactic Acid Bacteria as Complementary Treatments for Intestinal Inflammation. Anti-inflammatory \& anti-allergy agents in medicinal chemistry. Antiinflamm Antiallergy Agents Med Chem. 2018 May 2.

44. Niers et al. "The effects of selected probiotic strains on the development of eczema (the PandA study)." Allergy64.9 (2009): 1349-1358. 
45. Soh SE. Probiotic supplementation in the first 6 months of life in at risk Asian infants-effects on eczema and atopic sensitization at the age of 1 year. Clinic Experim Aller 2009; 39(4): 571-578.

46. Viljanen S. Probiotic effects on faecal inflammatory markers and on faecal IgA in food allergic atopic eczema/dermatitis syndrome infants. Pediatr Allergy Immunol. 2005; 16(1): 65-71.

47. Pornpimon K. Heterologous expression of a gene encoding cholesterol oxidase in probiotic strains of Lactobacillus plantarum and Propionibacterium freudenreichii under the control of native promoters. J Biosci Bioeng. 2001; 92(5): 459-465.

48. Hlivak P, Odraska J, Ferencik M, Ebringer L, Jahnova E, Mikes Z. One-year application of probiotic strain Enterococcus faecium M-74 decreases serum cholesterol levels. Bratisl Lek Listy 2005; 106(2): 67-72.

49. Davide R, Redaelli A. "Breast cancer management." Pharmacoeconomics 2003; 21(6): 383-396.

50. Berglund G, Nystedt M, Bolund C, Sjödén PO, Rutquist LE. Effect of endocrine treatment on sexuality in premenopausal breast cancer patients: a prospective randomized study. J Clin Oncol. 2001; 19(11): 2788-2796.

51. Day R, Ganz PA, Costantino JP, Cronin WM, Wickerham DL, Fisher B. Health-related quality of life and tamoxifen in breast cancer prevention: a report from the National Surgical Adjuvant Breast and Bowel Project P-1 Study. J Clin Oncol 1999; 17(9): 2659-2659.

52. Fallowfield F. Tamoxifen for the prevention of breast cancer: psychosocial impact on women participating in two randomized controlled trials. J Clin Oncol. 2001; 19(7): 18851892.

53. Mortimer J E, de Vries EG, van der Zee AG, ten Hoor KA. Effect of tamoxifen on sexual functioning in patients with breast cancer. J Clin Oncol 1999; 17: 1488-92.

54. Mor, Vincent, Maili Malin, Susan Allen. "Age differences in the psychosocial problems encountered by breast cancer patients. J Natl Cancer Inst Monogr. 1994; (16): 191-7.

55. Josée S. Cancer treatments and their side effects are associated with aggravation of insomnia: results of a longitudinal study. Cancer 2015; 121(10): 1703-1711.

56. Bentzen Søren M. Preventing or reducing late side effects of radiation therapy: radiobiology meets molecular pathology. Nat Rev Cancer 2006; 6(9): 702.

57. Allan James M, Lois B. Travis. Mechanisms of therapy-related carcinogenesis. Nat rev cancer 2005; 5(12): 943.

58. Wang M, Yin B, Wang HY, Wang RF. Current advances in T-cell-based cancer immunotherapy. Immunother. 2014; 6(12): 1265-78.

59. Carlson Matthew J, Kristina W. Thiel, Kimberly K. Leslie. Past, present, and future of hormonal therapy in recurrent endometrial cancer. Int J Womens Health 2014; (6): 429.

60. Prigerson et al. Chemotherapy use, performance status, and quality of life at the end of life. JAMA oncol. 2015; 1(6): 778784.

61. Michael D, Farwell MD. How Imaging Biomarkers Can Inform Clinical Trials and Clinical Practice in the Era of Targeted Cancer Therapy. JAMA Oncol. 2015; 1(4): 421-2.

62. Sun H. Oligonucleotide aptamers: new tools for targeted cancer therapy. Mol Ther Nucleic Acids. 2014; 1: 3.

63. Wang Yet. Potentiating bacterial cancer therapy using hy- droxychloroquine liposomes. J Control Release. 2018 May 4.

64. Gujrati V. Bioengineered bacterial outer membrane vesicles as cell-specific drug-delivery vehicles for cancer therapy. ACS nano. 2014; 15; 8(2): 1525-37.

65. Song J, Zhang Y, Wang Q. P1. 03-051 Development of a Novel Microfluidic Device for Studying the Chemotaxis Mechanism of Bacterial Cancer Targeting. J Thorac Oncol. 2017; 1; 12(11): 1970.

66. Chu M, Gao H, Sa Liu, Wang L, Jia Y, Gao M. Functionalization of composite bacterial cellulose with $\mathrm{C} 60$ nanoparticles for wound dressing and cancer therapy. RSC Adv. 2018; 8(33): 18197-203.

67. Gupta J, Bahadur D. Defect-Mediated Reactive Oxygen Species Generation in Mg-Substituted ZnO Nanoparticles: Efficient Nanomaterials for Bacterial Inhibition and Cancer Therapy. ACS Omega. 2018 12; 3(3): 2956-65.

68. Kramer MG, Masner M, Ferreira FA, Hoffman RM. BACTERIAL THERAPY OF CANCER: PROMISES, LIMITATIONS AND INSIGHTS FOR FUTURE DIRECTIONS. Front Microbiol. 2018; 9: 16.

69. Yin H. Non-viral vectors for gene-based therapy. Nat Rev Genet. 2014; 15(8): 541.

70. Naldini L. Gene therapy returns to centre stage. Nat. 2015; 526(7573): 351.

71. Husain SR, Han J, Au P, Shannon K, Puri RK. Gene therapy for cancer: regulatory considerations for approval. Cancer Gene Therapy. 2015; 22(12): 554.

72. Malekshah OM, Chen X, Nomani A, Sarkar S, Hatefi A. Enzyme/prodrug systems for cancer gene therapy. Current Pharmacology Reports. 2016 1; 2(6): 299-308.

73. Riglar DT, Silver PA. Engineering bacteria for diagnostic and therapeutic applications. Nat Rev Microbiol. 2018; 16(4):214.

74. Din MO et al. Synchronized cycles of bacterial lysis for in vivo delivery. Nat. 2016; 536(7614): 81.

75. Teo PY, Cheng W, Hedrick JL, Yang YY. Co-delivery of drugs and plasmid DNA for cancer therapy. Adv Drug Deliv Rev. 2016; 1; 98: 41-63.

76. Zheng DW, Chen Y, Zi-Hao Li, Xu L .Optically-controlled Bacterial Metabolite for Cancer Therapy. Nat Commun. 2018; 26; 9(1):1680.

77. Lin IY, Van TT, Smooker PM. Live-attenuated bacterial vectors: tools for vaccine and therapeutic agent delivery. Vaccines. 2015; 10; 3(4): 940-72.

78. Zitvogel L, Daillère R, Roberti MP, Routy B, Kroemer G. Anticancer effects of the microbiome and its products. Nat Rev Microbiol. 2017; 15(8): 465.

79. Felgner S, Kocijancic D, Frahm M, Weiss S. Bacteria in cancer therapy: renaissance of an old concept. Int J Microbiol. 2016; 7(2): 34.

80. Weidle UH. Prospects of bacterial and plant protein-based immunotoxins for treatment of cancer. Cancer Genomics-Proteomics. 2014; 1; 11(1): 25-38.

81. Hosseinidoust Z. Bioengineered and biohybrid bacteria-based systems for drug delivery. Adv Drug Deliv Rev. 2016; 15; 106: 27-44.

82. TaherianFard A. Cloning and expression of C-terminal of Clostridium perfringens type A enterotoxin and its biological activity. African J Microbiol Res. 2010; 4(14): 1469-1474.

83. Dalmasso G, Cougnoux A, Delmas J, Darfeuille-Michaud 
A, Bonnet R. The bacterial genotoxin colibactin promotes colon tumor growth by modifying the tumor microenvironment. Gut Microbes. 2014; 3; 5(5): 675-80.

84. Bachran C. Cytolethal distending toxin B as a cell-killing component of tumor-targeted anthrax toxin fusion proteins. Cell Death Dis. 2015; 5(1): 1003.

85. Dang $\mathrm{L}$ et al. Combination bacteriolytic therapy for the treatment of tumors. United States patent US 9,572,843. 2017 Feb 21.

86. Zhou S, Vogelstein B, Kinzler K, Kim K, Saha S, inventors; Johns Hopkins University, assignee. Use of bacteria, bacterial products, and other immunoregulatory entities in combination with anti-ctla- 4 and/or anti-pd-1 antibodies to treat solid tumor malignancies. United States patent application US 15/301,163. 2017 Jan 26.

87. Kubiak AM, Minton NP. The potential of clostridial spores as therapeutic delivery vehicles in tumour therapy. Res Microbiol. 2015; 1;166(4):244-54.

88. Fung TC, Artis D, Sonnenberg GF. Anatomical localization of commensal bacteria in immune cell homeostasis and disease. Immunol Rev. 2014; 1; 260(1): 35-49.

89. Louis P, Hold GL, Flint HJ. The gut microbiota, bacterial metabolites and colorectal cancer. Nat Rev Microbiol. 2014; 12(10): 661 .

90. Luo CH, Huang CT, Su CH, Yeh CS. Bacteria-mediated hypoxia-specific delivery of nanoparticles for tumors imaging and therapy. Nano letters. 2016; 9; 16(6): 3493-9.

91. Zhao F. Simultaneous inhibition of sulfate-reducing bacteria, removal of $\mathrm{H} 2 \mathrm{~S}$ and production of rhamnolipid by recombinant Pseudomonas stutzeri Rhl: Applications for microbial enhanced oil recovery. Bioresour Technol. 2016; 1; 207: 24-30.

92. Nallar SC, Xu DQ, Kalvakolanu DV. Bacteria and genetically modified bacteria as cancer therapeutics: Current advances and challenges. Cytokine. 2017; 89(1):160-72.

93. Torres $\mathrm{W}$ et al. Bacteria in cancer therapy: beyond immunostimulation. J Cancer Metastasis Treat 2018; 4: 4.

94. Chamekh M. Genetically Engineered Bacteria in Gene Therapy-Hopes and Challenges. Curr Gene Ther. 2015. InTech.

95. Taniguchi SI, Shimatani Y, Fujimori M. Tumor-targeting therapy using gene-engineered anaerobic-nonpathogenic Bifidobacterium longum. Bacterial Therapy of Cancer: Methods and Protocols. 2016: 49-60.

96. Kaimala S, Al Sbiei A, Cabral-Marques O, Fernandez-Cabezudo MJ, Al-Ramadi BK. Attenuated Bacteria as immunotherapeutic tools for cancer treatment. Front Oncol. 2018; 8: 136.

97. Podder S, Rakshit S, Ponnusamy M, Nandi D. Efficacy of Bacteria in Cancer Immunotherapy: Special Emphasis on the Potential of Mycobacterial Species. Clin Cancer Drugs. 2016 Oct $1 ; 3(2): 100-8$.

98. Staedtke V, Roberts NJ, Bai RY, Zhou S. Clostridium novyiNT in cancer therapy. Genes \& Diseases. 2016 Jun 1; 3(2):144-52.

99. Sarotra P, Medhi B. Use of bacteria in cancer therapy In Current Strategies in Cancer Gene Therapy. Springer, Cham, 2016; 111-121.

100. Shin MC. Recombinant TAT-gelonin fusion toxin: Synthesis and characterization of heparin/protamine-regulated cell transduction. J Biomed Mater Res A. 2015 Jan 1; 103(1):
409-19.

101. Konstantinopoulos PA, Ceccaldi R, Shapiro GI, D’Andrea AD. Homologous recombination deficiency: exploiting the fundamental vulnerability of ovarian cancer. Cancer Discov. 2015 Nov 1; 5(11):1137-54

102. Yeo CC, Abu Bakar F, Chan WT, Espinosa M, Harikrishna JA. Heterologous expression of toxins from bacterial toxin-antitoxin systems in eukaryotic cells: strategies and applications. Toxins. 2016 Feb 19; 8(2): 49.

103. Pires DP, Cleto S, Sillankorva S, Azeredo J, Lu TK. Genetically engineered phages: a review of advances over the last decade. Microbiol Mol Biol Rev. 2016 Sep 1; 80(3): 523-43.

104. McFadden DG et al. Mutational landscape of EGFR-, MYC, and Kras-driven genetically engineered mouse models of lung adenocarcinoma. Proceedings National Academy Sci. 2016 Oct 18; 113(42): 6409-17.

105. Bachanova V et al. Phase I study of a bispecific ligand-directed toxin targeting CD22 and CD19 (DT2219) for refractory B-cell malignancies. Clin Cancer Res. 2015 Mar 15; 21(6):1267-72.

106. Jones P, Wilcoxen K, Rowley M, Toniatti C. Niraparib: a poly (ADP-ribose) polymerase (PARP) inhibitor for the treatment of tumors with defective homologous recombination. J Med Chem. 2015 Apr 23; 58(8):3302-14

107. Piñero-Lambea C, Ruano-Gallego D, Fernández LÁ. Engineered bacteria as therapeutic agents. Curr Opin Biotechnol. 2015 Dec 1; 35: 94-102.

108. Mobergslien A et al. Recombinant Lactobacillus plantarum induces immune responses to cancer testis antigen NYESO-1 and maturation of dendritic cells. Hum Vaccin Immunother. 2015 Nov 2; 11(11):2664-73.

109. Han JW et al. Active tumor-therapeutic liposomal bacteriobot combining a drug (paclitaxel)-encapsulated liposome with targeting bacteria (Salmonella Typhimurium). Sens Actuators B Chem. 2016 Mar 1; 224: 217-24.

110. Hoffman RM, Zhao M. Methods for the development of tumor-targeting bacteria. Expert Opin Drug Discov. 2014 Jul $1 ; 9(7): 741-50$.

111. Murakami T et al. Tumor-targeting Salmonella typhimurium A1-R in combination with doxorubicin eradicate soft tissue sarcoma in a patient-derived orthotopic xenograft (PDOX) model. Oncotarget. 2016 Mar 15; 7(11): 12783.

112. Zhang Y, Miwa S, Zhang N, Hoffman RM, Zhao M. Tumor-targeting Salmonella typhimurium A1-R arrests growth of breast-cancer brain metastasis. Oncotarget. 2015 Feb; 6(5):2615.

113. Hoffman RM. Back to the future: are tumor-targeting bacteria the next-generation cancer therapy?. Gene Therapy of Solid Cancers: Methods and Protocols. 2015:239-60.

114. Hoffman RM. Bacterial therapy of cancer: Methods and protocols. Springer; 2016

115. Kiyuna T et al. High efficacy of tumor-targeting Salmonella typhimurium A1-R on a doxorubicin-and dactolisib-resistant follicular dendritic-cell sarcoma in a patient-derived orthotopic xenograft PDOX nude mouse model. Oncotarget. 2016 May 31; 7(22): 33046.

116. Hiroshima Y et al. Tumor-targeting Salmonella typhimurium A1-R arrests a chemo-resistant patient soft-tissue sarcoma in nude mice. PloS One. 2015 Aug 3; 10(8): 0134324.

117. [117] Collignon J, Lousberg L, Schroeder H, Jerusalem G. Triple-negative breast cancer: treatment challenges and 
solutions. Breast Cancer: Targets Ther. 2016; 8:93.

118. [118] Zugazagoitia $J$ et al. Current challenges in cancer treatment. Clin Ther. 2016 Jul 1; 38(7): 1551-66.

119. [119] Shin MC, Zhang J, Ah Min K, Lee K, Byun Y, E David A, He H, C Yang V. Cell penetrating peptides: Achievements and challenges in application for cancer treatment. J Biomed Mater Res A. 2014 Feb 1; 102(2):575-87.

120. [120] Zhao M, Yang M, Li XM, Jiang P, Baranov, Shukuan Li E, Xu M, Penman SH, M Hoffman R. Tumor-targeting bacterial therapy with amino acid auxotrophs of GFP-expressing Salmonella typhimurium. Proc Natl Acad Sci U S A. 2005 Jan 18; 102(3): 755-60.

121. [121] Iida N. Commensal bacteria control cancer response to therapy by modulating the tumor microenvironment. Sci. 2013 Nov 22; 342(6161):967-70.

122. [122] Kievit E. Superiority of yeast over bacterial cytosine deaminase for enzyme/prodrug gene therapy in colon cancer xenografts. Cancer res. 1999 Apr 1; 59(7):1417-21.

123. [123] Anderson JC, Clarke EJ, Arkin AP, Voigt CA. Environmentally controlled invasion of cancer cells by engineered bacteria. J mol biol. 2006 Jan 27; 355(4): 619-27.

124. [124] Fox ME et al. Anaerobic bacteria as a delivery system for cancer gene therapy: in vitro activation of 5-fluorocytosine by genetically engineered clostridia. Gene thera. 1996 Feb; 3(2):173-8.

125. [125] Cometta A, Calandra T, Gaya H, Zinner SH, Bock RD, Del Favero A, Bucaneve G, Crokaert F, et al. Monotherapy with meropenem versus combination therapy with ceftazidime plus amikacin as empiric therapy for fever in granulocytopenic patients with cancer. The International Antimicrobial Therapy Cooperative Group of the European Organization for Research and Treatment of Cancer and the Gruppo Italiano Malattie Ematologiche Maligne dell'Adulto Infection Program. Antimicrob Agents Chemother. 1996 May 1; 40(5): 1108-15. 